\section{Do travel brochures give adequate advice on avoiding illness?}

There has been a spectacular growth in the number of travellers world wide over the past 35 years (table) and the World Tourism Organisation predicts that the number of international tourists will reach 480 million by 1990 . Travel to the developing regions is expected to show the highest growth rate (about 10\%-almost twice the world average).

\section{Growth in international travel}

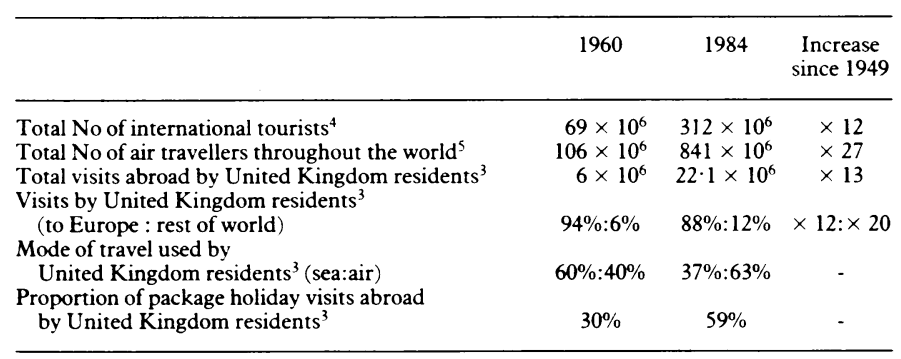

Studies of illness in travellers show attack rates of $30 \%$ to over $50 \%$, varying with age, lifestyle, season, and country visited.' Attacks usually comprise a mild diarrhoeal upset which rarely results in more than a minor self limiting inconvenience, but more serious illnesses acquired abroad-for example, malaria ${ }^{2}$ - continue to be recorded. We have conducted a survey assessing the measures taken by the travel trade to address this problem and protect the health interests of their clients.

\section{Methods and results}

We collected 64 travel brochures from the public display of an established independent travel agency in the city centre of Glasgow. The brochures represented all the main tour operators and carriers covering destinations throughout the world, including cruises, and were readily available to prospective holidaymakers from the west of Scotland. Brochures were categorised according to the season of the advertised vacation and the destination. We classified health information as "specific" when it included details of specific immunisation recommendations or of particular environmental or climatic conditions in the holiday destination relevant to maintaining good health. "General" health information recommended seeking further advice from the family doctor, local health department, or embassy of the country to be visited.

Twenty one of the 64 brochures studied (33\%) carried no health information for travellers. Brochures covering all year round travel $(23 ; 36 \%)$ included the highest proportion $(83 \%)$ with health information. The smallest group of brochures $(19 ; 30 \%)$ covered winter travel and had the least health information $(53 \%)$.

The largest number of brochures $(29 ; 45 \%)$ related to European travel and included the lowest proportion with health information for travellers $(38 \%)$, none of which was specific for the travel destination. Worldwide travel was covered by 15 brochures (23\%), all of which carried health information but only four with specific advice. Altogether 36 brochures $(56 \%)$ carried general and $7(11 \%)$ specific health information.

Ten of the brochures covered cruise ships, nine sailing all year round and five to worldwide destinations. There was no health information in three of these brochures but all stated that qualified medical and paramedical personnel accompanied the cruise.

\section{Comment}

Most people going abroad from the United Kingdom travel on inclusive package holidays. ${ }^{3}$ Hence the attitude of package tour operators towards the health of their clients while abroad is of prime importance.

In view of the amount of illness associated with travel it gives cause for concern that a third of the 1985 brochures analysed carried no health advice for travellers. Winter travellers and travellers to Europe were likely to have even less guidance $(47 \%$ and $62 \%$ of brochures, respectively, without health advice). "Specific" health advice was inconsistent. Some brochures carried general recommendations on immunisations, dietary caution, and the use of antimalarial tablets; others were both more and less specific for the same destination country. Reciprocal health arrangements with the National Health Service were mentioned occasionally.
That all the brochures carried promotional information to help travellers insure against medical misfortune while abroad shows that tour operators are aware of health needs. Given this discrepancy when viewed against the inadequacies and inconsistencies in the health information in the brochures studied, there seems to be common ground where health educators and the medical profession could collaborate with the travel trade for the benefit of all concerned.

The help of Mrs N Wilson, Mrs L Kidd, Messrs Donald Mackenzie (Travel) Ltd, and the Scottish Health Education Group is much appreciated.

1 Cossar JH, Reid D, Grist NR, et al. Illness associated with international travel: a ten year review. Travel Medicine International 1985;3(1):13-8.

2 Public Health Laboratory Service Malaria Reference Laboratory and Communicable Disease Surveillance Centre. Malaria in Britain: 1982. Br Med J 1983;287:1789.

3 Business Statistics Office. Business monitor annual statistics. Overseas travel and tourism. [MA6.] London: HMSO, 1960, 1984.

4 World Tourism Organisation. Tourism compendium. Madrid: Gráficas M Fcc, SL:1981, 1985.

5 International Civil Aviation Organisation. Development of civil air transport 1945-1985. Statistics. Montreal: ICAO, 1986.

(Accepted 15 September 1986)

Communicable Diseases (Scotland) Unit, Ruchill Hospital, Glasgow G20 9NB

D REID, MD, FRCPGLAS, director

J H COSSAR, MB, CHB, research associate

T I AKO, MB, MPH, research assistant

R D DEWAR, senior administrative assistant

Correspondence to: Dr Cossar.

\section{Recent trends in mortality associated with abuse of volatile substances in the UK}

In 1985 we reported on 282 deaths associated with abuse of volatile substances that occurred between 1971 and $1983 .^{\prime}$ Trends were difficult to determine because our methods of investigation had not been consistent. We have been using the same methods, however, to detect deaths from abuse of volatile substances over the past five years and may now examine trends.

Attempts have been made in recent years to curb the abuse of volatile substances, including legislation and voluntary codes of practice concerning the sale and display of certain products and the dissemination of information to professionals, parents, and children. We examined our data for the five years 1981-5 to identify the current trends and determine whether recent control measures have had any effect.

\section{Methods and results}

Our methods of investigation, which have been described previously, ${ }^{1}$ rely mainly on a systematic survey of newspapers by a press clipping agency; regular surveys of coroners; and liaison with the Office of Population Censuses and Surveys and, in Scotland, the Crown Office. Inquest proceedings, necropsy reports, and toxicology findings are sought in all cases and obtained in most. This paper concentrates on trends in numbers nationally and regionally, age and sex distribution, the various substances abused, and the cause of death. Significance was measured using the $\chi^{2}$ test.

There were 385 deaths during the five years, the yearly number increasing from 46 in 1981 to 116 in 1985 . Regional trends varied, and a comparison of the numbers for the two years $1982-3$ and those for 1984-5 shows that deaths occurring in Wales and the Northern, Yorkshire and Humberside, and West Midlands regions doubled, while there were smaller increases in Scotland and Northern Ireland and no increase in the south east. Most of those who died (285 $(74 \%)$ ) were under the age of 20 , and $65(17 \%)$ were aged $10-14$. We found no trend in the age or sex distribution of deaths, and there was no change during the period in the proportion of deaths associated with the different substances, with an increase in numbers occurring in all major categories (table). Overall, gas fuels (mainly butane); solvents in glues (mainly toluene); and "other solvents" (principally plaster removers and correcting fluid thinners-mainly $1,1,1$ trichloroethane) each accounted for around $30 \%$ of deaths.

In $43 \%$ of cases death was attributed to the direct toxic effects of the substance. The remaining deaths were thought to have resulted from intoxicated behaviour (trauma 15\%), the method of inhalation (plastic bag over the head $16 \%$ ), or inhalation of stomach contents $(16 \%)$. There was a significant downward trend 
BRITISH MEDICAL JOURNAL VOLUME $293 \quad 6$ DECEMBER 1986

No (\%) of deaths associated with abuse of various volatile substances in the United Kingdom 1981-5

\begin{tabular}{|c|c|c|c|c|c|c|}
\hline & 1981 & 1982 & 1983 & 1984 & 1985 & Total \\
\hline Gas fuels & $15(33)$ & $11(18)$ & $19(24)$ & $31(38)$ & $30(26)$ & $106(28)$ \\
\hline Aerosol sprays & $1(2)$ & $8(13)$ & $12(15)$ & $9(11)$ & $20(17)$ & $50(13)$ \\
\hline Solvents in glue & $16(35)$ & $18(29)$ & $24(30)$ & $15(19)$ & $35(30)$ & $108(28)$ \\
\hline $\begin{array}{l}\text { Other volatile } \\
\text { substances }\end{array}$ & $13(28)$ & $24(39)$ & $25(31)$ & $26(32)$ & $28(24)$ & $116(30)$ \\
\hline $\begin{array}{c}\text { Substances- } \\
\text { unknown }\end{array}$ & 1 (2) & $1(2)$ & 0 & 0 & $3(3)$ & $5(1)$ \\
\hline Total & 46 & 62 & 80 & 81 & 116 & 385 \\
\hline
\end{tabular}

$(p<0.01)$ in deaths associated with plastic bags from around $20 \%$ to $10 \%$; otherwise no trend in the cause of death was observed.

\section{Comment}

Our data were collected using consistent methods over five years. Thus though knowledge of, and interest in, the problem has grown, there has probably been a real increase in the number of deaths. This contradicts the belief that the abuse of volatile substances is a passing fashion. Our evidence indicates that the various efforts which have been made to prevent abuse and reduce the risk of death among abusers have not affected the scale of the problem, the pattern of substances abused, or the risk of accidental death among those abusing volatile substances.

The collection of these data was supported by the Department of Health and Social Security.

1 Anderson HR, Macnair RS, Ramsey JD. Deaths from abuse of volatile substances: a national epidemiological study. Br Med f 1985;290:304-7.

(Accepted 11 September 1986)

St George's Hospital Medical School, London SW17 0RE

H R ANDERSON, MD, FFCM, head of department of clinical epidemiology and social medicine.

K BLOOR, BSC, research organiser, department of clinical epidemiology and social medicine

R S MACNAIR, SRN, research organiser, department of clinical epidemiology and social medicine

J RAMSEY, head of toxicology unit, department of chemical pathology

Correspondence to: Professor Anderson.

\section{Widespread use of condoms and low prevalence of sexually transmitted diseases in Danish non-drug addict prostitutes}

In the Western World infection with the human immunodeficiency virus occurs in particular risk groups-for example, male homosexuals and intravenous drug abusers. ' Though hepatitis $B$, which occurs with a high incidence among male homosexuals, has not spread to the general population, the epidemic of acquired immune deficiency syndrome (AIDS) may not respect the boundaries of sexual orientation. This is supported by the high prevalence of antibodies to human immunodeficiency virus found among female prostitutes in both central and east Africa. ${ }^{23}$

We have investigated the prevalence of markers of sexually transmitted diseases, sexual behaviour, and the use of condoms in a group of Danish nondrug addict female prostitutes.

\section{Subjects, methods, and results}

Study participants were recruited by contacting prostitutes advertising in Copenhagen newspapers and magazines (roughly 400). During August to October 1985, 101 prostitutes were interviewed and examined serologically. The study was approved by the local ethical committee.

Antibodies to human immunodeficiency virus (anti-HIV) and hepatitis B surface antigen ( $\mathrm{HBsAg}$ ) and antibody (anti-HBs) were assayed by radioimmunoassay (Abbott, Illinois). Antibodies to cytomegalovirus were assayed by enzyme linked immunosorbent assay. Serum samples were also examined for the cardiolipin Wassermann reaction (Mörch) and by the automated reagin test.

All but two of the subjects were white. Their median age was 28 years (range 19-60) and the median duration of prostitution 24 months (range 1 month to 26 years). Twenty six of the subjects worked as escorts and 75 worked in massage parlours. Ten women also had occasional contacts in night clubs. One subject admitted intravenous drug abuse.

The table gives details of previous sexually transmitted diseases in the group, markers of sexually transmitted diseases detected, and the sexual practices of the women. The prevalence of markers of hepatitis B virus infection was similar to that among Danish blood donors, and the prevalence of markers of infection with cytomegalovirus was not significantly different from that in a group of Danish women blood donors of similar age distribution (C M Nielsen, unpublished).

Sexually transmitted diseases and sexual behaviour in 101 Danish non-drug addict female prostitutes (recruited from massage parlour and escort service agencies)

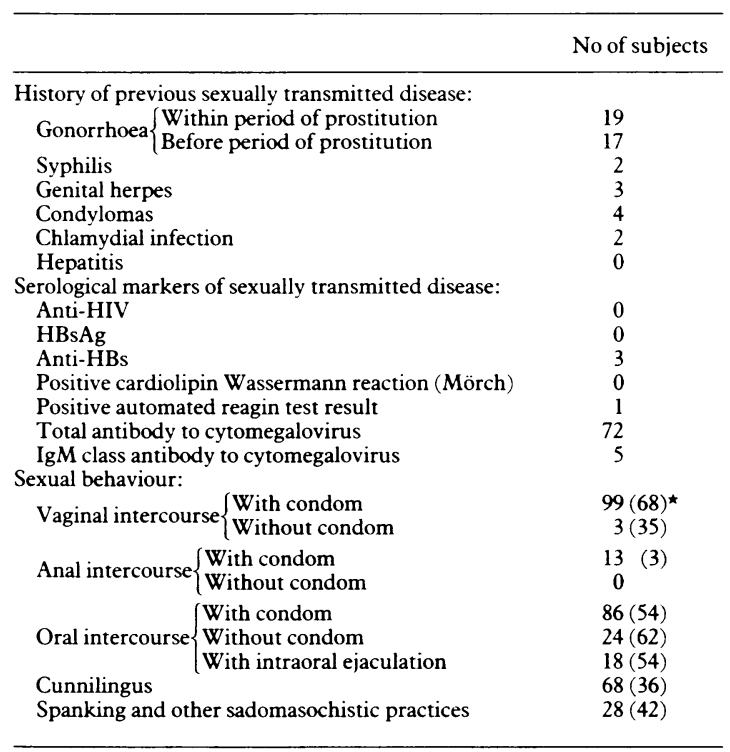

*Figures in parentheses are mean percentage of sexual encounters in which behaviour was practised.

The median number of sexual encounters a week was 20 (range $<1-100$ ). Twenty five of the women suspected that up to one fifth of their clients were homosexual or bisexual, and 37 occasionally had clients from the United States, Africa, or the Caribbean.

\section{Comment}

This study found no evidence of infection with the human immunodeficiency virus in Danish non-drug addict prostitutes. Furthermore, the prevalence of hepatitis $B$ virus infection and markers of cytomegalovirus infection in these women was not significantly different from that among non-prostitute women. These observations may partly be explained by the widespread use of condoms, which in some measure protect against sexually transmitted diseases. In addition, evidently men visiting prostitutes are often middle aged (data not shown) and may have only few extramarital relations. Thus clients are probably not part of a promiscuous community in which all have a high frequency of new sexual contacts.

Our series was biased towards prostitutes concerned about the risks of sexually transmitted diseases, so presumably they practised safer sex (use of condoms) than others. Nevertheless, the nil prevalence of anti-HIV agrees with recent preliminary observations from England, France, and Italy. ${ }^{4}$

A prerequisite for the introduction of human immunodeficiency virus infection among prostitutes is direct or indirect contact with a community in which this infection is prevalent. Surprisingly, a quarter of the prostitutes suspected that some of their clients were homosexual or bisexual. This, however, was often based on clients who wished to engage in active or passive (the prostitute using a dildo) anal intercourse. A minority knew that some of their clients were homosexual. In these cases only non-genital (spanking) practices were employed. The possibility of indirect contact between the study group and drug addict prostitutes infected with the human immunodeficiency virus ${ }^{5}$ was beyond the scope of this study.

In conclusion, we think that the low prevalence of sexually transmitted diseases in this group may partly be explained by the widespread use of condoms. 